\title{
Volatiles Profiling, Allelopathic Activity, and Antioxidant Potentiality of Xanthium Strumarium Leaves Essential Oil from Egypt: Evidence from Chemometrics Analysis
}

\author{
Ahmed Abd El-Gawad ${ }^{1,2, *} \mathbb{C}$, Abdelsamed Elshamy ${ }^{3,4}{ }^{\oplus}$, Abd El-Nasser El Gendy ${ }^{5}{ }^{\circledR}$, \\ Ahmed Gaara ${ }^{3}$ and Abdulaziz Assaeed ${ }^{1}$ \\ 1 Plant Production Department, College of Food \& Agriculture Sciences, King Saud University, \\ Riyadh 11451, Saudi Arabia; assaeed@ksu.edu.sa \\ 2 Department of Botany, Faculty of Science, Mansoura University, Mansoura 35516, Egypt \\ 3 Department of Natural Compounds Chemistry, National Research Centre, 33 El Bohouth St., Dokki, \\ Giza 12622, Egypt; elshamynrc@yahoo.com (A.E.); ahmedgaara2003@live.com (A.G.) \\ 4 Faculty of Pharmaceutical Sciences, Tokushima Bunri University, Yamashiro-cho, \\ Tokushima 770-8514, Japan \\ 5 Medicinal and Aromatic Plants Research Department, National Research Centre, 33 El Bohouth St., Dokki, \\ Giza 12622, Egypt; aggundy_5@yahoo.com \\ * Correspondence: aibrahim2@ksu.edu.sa or dgawad84@mans.edu.eg; \\ Tel.: +201-003-438-980 or +966-562-680-864
}

Academic Editor: Francesca Mancianti

Received: 22 January 2019; Accepted: 5 February 2019; Published: 7 February 2019

\begin{abstract}
The essential oil (EO) of Xanthium strumarium L. leaves (family: Asteraceae) was extracted by hydrodistillation, and then analyzed by gas chromatography-mass spectrometry (GC-MS). Forty-three essential compounds were identified. The sesquiterpenoids represented the major constituents $(72.4 \%)$, including oxygenated $(61.78 \%)$ and non-oxygenated $(10.62 \%)$ sesquiterpenes, followed by monoterpenes $(25.19 \%)$. The diterpenoids and oxygenated hydrocarbons were determined as minor compounds. The main constituents of the EO were 1,5-dimethyltetralin $(14.27 \%)$, eudesmol (10.60\%), l-borneol (6.59\%), ledene alcohol (6.46\%), (-)-caryophyllene oxide (5.36\%), isolongifolene, 7,8-dehydro-8a-hydroxy (5.06\%), L-bornyl acetate (3.77\%), and aristolene epoxide $(3.58 \%)$. A comparative analysis was stated here between the EO of Egyptian X. strumarium and those previously reported from Pakistan, Iran, and Brazil based on chemometic tools such as principal components analysis (PCA) and agglomerative hierarchical clustering (AHC). The EO of X. strumarium showed weak 1, 1-diphenyl-2-picryl hydrazyl (DPPH) radical scavenging activity with $\mathrm{IC}_{50} 321.93 \mu \mathrm{L} / \mathrm{L}^{-1}$, which was comparable to ascorbic acid as a reference. However, the EO exhibited significant allelopathic potential regarding the germination and growth of the noxious weed Bidens pilosa in a concentration-dependent manner. Therefore, further study is recommended to characterize the EO from X. strumarium as an eco-friendly green bioherbicide against weeds, as well as determine their mode of actions.
\end{abstract}

Keywords: Xanthium strumarium; essential oil; PCA; AHC; phytotoxicity; antioxidant activity

\section{Introduction}

From ancient times, the essential oils (EOs) of herbal plants and other plant extracts have attracted the attention and interest of researchers as sources of bioactive natural products. EOs were reported to exhibit several significant biological activities as antioxidant and antimicrobial agents as well as 
have the potential for food preservation [1,2]. The free radicals play a critical role in human health in relation to oxidative stress; they damage the cell components, resulting in cellular and metabolic injury in the form of inflammation, as well as cardiovascular and cancer diseases [2].

On the other hand, using synthetic herbicides has exhibited harmful effects on the environment, and therefore human health, in addition to the appearance of herbicide-resistant weeds [3]. Nowadays, allelopathy from different parts of plant materials offers significant sources for selective biological weed management through the release and production of allelochemicals [4]. The EOs produced from different plant parts provide an ecological advantage such as protection against predators, determinants of vegetation patterning, pollinator attractants, and the mediation of plant-plant interactions, including allelopathy [5-7]. EOs have been recommended as potent agents for retarding plant growth and inhibiting seed germination $[8,9]$.

The species belonging to Xanthium genus (family: Asteraceae) were reported to exhibit several bioactivities such as antimalarial [10], cytotoxicity [11], insecticidal [12], fungicidal [13], antiviral [14], and antibacterial [15]. The annual herbal plant X. strumarium L. is widely distributed around the world, especially in Africa, Asia, and Europe. Xanthium strumarium (Cocklebur) was used in folklore medicine for the treatment of headache, arthritis, urticaria, emphysema, sinusitis, diuretic, sedative, and diaphoretic ailments [16-18]. This plant is used in the manufacturing of yellow dye, which is used as hair dye; from this, the genus took the name, as xanthos means yellow in Greek [19]. The chemical constituents of X. strumarium are enriched with phenolics [16], steroids, triterpenoid saponins [20], monoterpene, sesquiterpene [21,22], and EO [23-25].

According to our knowledge, no study has yet revealed the composition of EOs from Egypt. Herein, the goals of our study were (i) identification of the chemical constituents of the EO of X. strumarium leaves collected from Egypt, (ii) comparison the EO of Egyptian X. strumarium with those previously documented from Pakistan, Iran, and Brazil, depending upon principal components analysis (PCA) and agglomerative hierarchical clustering (AHC), (iii) evaluation of the allelopathic potential of the $\mathrm{EO}$ on the germination and growth of the noxious weed Bidens pilosa and (iv) assessment of antioxidant activity of the EO.

\section{Results and Discussion}

\subsection{Chemical Constituents of EO of the Leaves of X. Strumarium}

Forty-three compounds were identified, which represented 100\% of the total mass (Figure 1 and Table 1). Four classes of organic essential components (monoterpenes, sesquiterpenes, diterpenes, and oxygenated hydrocarbons) were identified.

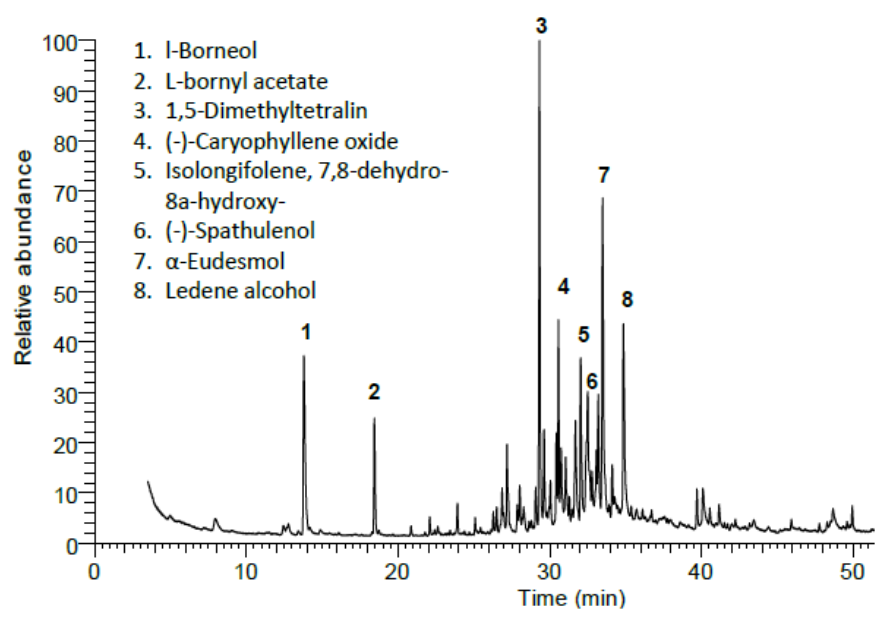

Figure 1. Gas chromatography-mass spectrometry (GC-MS) chromatogram of essential oil (EO) from the leaves of Egyptian X. strumarium. The peaks with numbers represent the major compounds. 
Table 1. Chemical composition of the EO of X. strumarium leaves collected from Egypt analyzed by GC-MS.

\begin{tabular}{|c|c|c|c|c|c|}
\hline No & $\mathrm{RT}^{\mathrm{a}}$ & $\mathbf{K I}^{\mathbf{b}}$ & $\mathrm{KI}^{\mathrm{c}}$ & Compound Name & Conc. $(\%)^{d}$ \\
\hline \multicolumn{6}{|c|}{ Non-oxygenated Monoterpenoids } \\
\hline 1 & 29.32 & 1341 & 1343.4 & 1,5-Dimethyltetralin & $14.27 \pm 0.04$ \\
\hline \multicolumn{6}{|c|}{ Oxygenated Monoterpenoids } \\
\hline 2 & 7.93 & 1346 & 1341.4 & $\alpha$-Terpinyl acetate & $0.56 \pm 0.01$ \\
\hline 3 & 13.78 & 1165 & 1161.9 & 1-Borneol & $6.59 \pm 0.02$ \\
\hline 4 & 18.44 & 1285 & 1266.1 & L-bornyl acetate & $3.77 \pm 0.03$ \\
\hline \multicolumn{6}{|c|}{ Non-oxygenated sesquiterpenoids } \\
\hline 5 & 20.86 & 1374 & 1319.9 & $\alpha$-Copaene & $0.34 \pm 0.01$ \\
\hline 6 & 22.08 & 1351 & 1347.1 & $\alpha$-Cubebene & $0.57 \pm 0.01$ \\
\hline 7 & 22.62 & 1431 & 1359.2 & $\beta$-Copaene & $0.39 \pm 0.01$ \\
\hline 8 & 23.91 & 1415 & 1388 & Caryophyllene & $0.91 \pm 0.02$ \\
\hline 9 & 26.27 & 1476 & 1442.2 & $\gamma$-Muurolene & $0.56 \pm 0.01$ \\
\hline 10 & 26.49 & 1482 & 1447.4 & Germacrene-D & $0.75 \pm 0.01$ \\
\hline 11 & 26.86 & 1492 & 1455.8 & $\beta$-Selinene & $1.16 \pm 0.02$ \\
\hline 12 & 26.97 & 1499 & 1458.6 & $\beta$-Guaiene & $0.34 \pm 0.01$ \\
\hline 13 & 28.02 & 1513 & 1483.8 & $\beta$-Cadinene & $1.36 \pm 0.03$ \\
\hline 14 & 28.28 & 1517 & 1488.8 & Trans-calamenene & $0.91 \pm 0.01$ \\
\hline 15 & 28.64 & 1474 & 1497.2 & $\gamma$-Himachalene & $0.29 \pm 0.01$ \\
\hline 16 & 29.07 & 1537 & 1507.5 & $\alpha$-Calacorene & $1.34 \pm 0.02$ \\
\hline \multicolumn{6}{|c|}{ Oxygenated Sesquiterpenoids } \\
\hline 17 & 27.18 & 1763 & 1759.3 & Aristolone & $2.84 \pm 0.04$ \\
\hline 18 & 29.94 & 1525 & 1528.4 & 9-Methoxycalamenene & $0.22 \pm 0.01$ \\
\hline 19 & 30.04 & 1578 & 1531 & 1,5-Epoxysalvial-4(14)-ene & $1.48 \pm 0.03$ \\
\hline 20 & 30.44 & 1576 & 1540.6 & Spathulenol & $2.49 \pm 0.02$ \\
\hline 21 & 30.57 & 1580 & 1543.8 & (-)-Caryophyllene oxide & $5.36 \pm 0.04$ \\
\hline 22 & 30.75 & 1530 & 1548.1 & Globulol & $2.21 \pm 0.02$ \\
\hline 23 & 31.05 & 1504 & 1555.2 & Salvial-4(14)-en-1-one & $1.83 \pm 0.02$ \\
\hline 24 & 31.46 & 1631 & 1595.2 & Aromadendrene oxide-(2) & $0.36 \pm 0.01$ \\
\hline 25 & 31.69 & 1671 & 1667.9 & Calarene epoxide & $3.52 \pm 0.03$ \\
\hline 26 & 32.04 & 1537 & 1579.4 & $\begin{array}{c}\text { Isolongifolene, } \\
\text { 7,8-dehydro-8a-hydroxy- }\end{array}$ & $5.06 \pm 0.03$ \\
\hline 27 & 32.5 & 1608 & 1591.9 & (-)-Spathulenol & $7.54 \pm 0.03$ \\
\hline 28 & 32.78 & 1582 & 1597.3 & Isoaromadendrene epoxide & $0.94 \pm 0.01$ \\
\hline 29 & 33.07 & 1636 & 1604.5 & Tau-Muurolol & $1.76 \pm 0.02$ \\
\hline 30 & 33.19 & 1763 & 1747.6 & Aristolene epoxide & $3.58 \pm 0.03$ \\
\hline 31 & 33.49 & 1654 & 1615.4 & $\alpha$-Eudesmol & $10.60 \pm 0.03$ \\
\hline 32 & 33.92 & 1729 & 1726.1 & Murolan-3,9(11)-diene-10-peroxy & $0.37 \pm 0.01$ \\
\hline 33 & 34.11 & 1548 & 1547.8 & Diepicedrene-1-oxide & $1.53 \pm 0.02$ \\
\hline 34 & 34.85 & 1729 & 1739.7 & Ledene alcohol & $6.46 \pm 0.03$ \\
\hline 35 & 42.24 & 1775 & 1756.3 & Furoscrobiculin B & $0.30 \pm 0.01$ \\
\hline 36 & 48.67 & 2005 & 2045.9 & Isochiapin B & $0.53 \pm 0.01$ \\
\hline 37 & 29.62 & 1653 & 1636.8 & $(+)-\gamma$ - Costol & $2.80 \pm 0.03$ \\
\hline \multicolumn{6}{|c|}{ Diterpenoids } \\
\hline 38 & 39.7 & 2218 & 2215.6 & E-Phytol, acetate & $0.49 \pm 0.01$ \\
\hline 39 & 47.78 & 2017 & 2018.4 & Kaur-16-ene, $(8 \beta, 13 \beta)$ - & $0.29 \pm 0.01$ \\
\hline \multicolumn{6}{|c|}{ Oxygenated hydrocarbons } \\
\hline 40 & 27.86 & 1512 & 1517.1 & Di-tert-Butylphenol & $0.85 \pm 0.01$ \\
\hline 41 & 40.08 & 1840 & 1834.7 & $\begin{array}{l}\text { 2-Pentadecanone, } \\
\text { 6,10,14-trimethyl- }\end{array}$ & $1.23 \pm 0.02$ \\
\hline 42 & 40.55 & 2566 & 2561.1 & Cis-13,16-Docasadienoic acid & $0.52 \pm 0.01$ \\
\hline 43 & 41.15 & 2276 & 2278.9 & $\begin{array}{l}\text { 11,14-Eicosadienoic acid, } \\
\text { methyl ester }\end{array}$ & $0.73 \pm 0.01$ \\
\hline
\end{tabular}

${ }^{\mathrm{a}}=$ Retention time; ${ }^{\mathrm{b}}=$ Kovats retention index on DB- 5 column in reference to $n$-alkanes; ${ }^{\mathrm{c}}=$ Experimental Kovates retention index; ${ }^{\mathrm{d}}=$ Values are mean \pm standard deviation. 
The gas chromatography-mass spectrometry (GC-MS) of the EO exhibited that this plant is very enriched with monoterpenoids $(25.19 \%)$, including both non-oxygenated $(14.27 \%)$ and oxygenated $(10.92 \%)$ types. Non-oxygenated monoterpenes are represented by only one compound (1,5-dimethyltetralin). However, the oxygenated monoterpenes were represented by l-borneol (6.59\%) and L-bornyl acetate (3.77\%) as majors, while $\alpha$-terpinyl acetate $(0.56 \%)$ was detected as a minor.

The sesquiterpenes represented the major components by a ratio of $72.40 \%$. The identified sesquiterpenoids were classified into two classes, including oxygenated and non-oxygenated types with a ratio of $61.78 \%$ and $10.62 \%$ respectively. The major constituents in the identified non-oxygenated sesquiterpenes were $\beta$-cadinene $(1.36 \%), \alpha$-calacorene $(1.34 \%)$, and $\beta$-selinene $(1.16 \%)$, but $\gamma$-himachalene $(0.29 \%)$ was identified as a minor one. However, eudesmol $(10.60 \%)$, ledene alcohol (6.46\%), (-)-caryophyllene oxide (5.36\%), and isolongifolene 7,8-dehydro-8a-hydroxy (5.06\%) represented the main components of the oxygenated sesquiterpenes. Also, aristolene epoxide $(3.58 \%)$, calarene epoxide $(3.52 \%)$, and aristolone $(2.84 \%)$ were identified with high ratios from the total mass of oxygenated sesquiterpenes, while 9-methoxycalamenene $(0.22 \%)$ represented the minor component.

Diterpenoids represented only $0.78 \%$ of the total mass, with only two identified compounds, which were characterized as phytol acetate $(0.49 \%)$ and $(8 \beta, 13 \beta)$-kaur-16-ene $(0.29 \%)$. Overall, the GC-MS results exhibited that the leaves of X. strumarium are very enriched with terpenoids by $98.37 \%$ of the total mass.

The oxygenated hydrocarbons with a small ratio of $3.33 \%$ of the total mass were also characterized. Only four compounds were identified as oxygenated hydrocarbons, including 6,10,14-trimethyl-2-pentadecanone $(1.23 \%)$ as a major, while cis- 13,16 -docasadienoic acid $(0.52 \%)$ was detected as a minor compound.

The chemical composition of EOs is complex and very rich with several bioactive substances [26] such as monoterpenes, sesquiterpenes, diterpenes, hydrocarbons, and their aldehyde and phenolic derivatives. The concentrations and chemical constituents of EOs of the aromatic herbal plants depended upon several environmental factors such as plant species, geographical sources, soil, climatic conditions, weather, seasons of the year, and vegetative cycle stages $[27,28]$. Also in plant species, a strong direct relation was deduced between the EOs and the pollination, seeds dissemination, and defense routes against attacks of herbivores as well as microorganisms such as fungi and bacteria [29,30].

Several reports described the constituents and biological activities of EO from the leaves of X. strumarium collected from Pakistan [24], Iran [23,25], and Brazil [31]. In harmony with our study, all of them are very commonly enriched with different classes of essential compounds, especially monoterpenes and sesquiterpenes. According to these previous studies, we described here for the first time the chemical constituents of the leaves of X. strumarium collected from Egypt. Our findings were in agreement with those previously reported studies (Figure 2). Esmaeili et al. [23] and Sharifi-Rad et al. [25] reported that the EO from leaves of Iranian (Iran-Sistan and Iran-Lurestan) $X$. strumarium are enriched with mono and sesquiterpenes as two main classes of components by $46.60 \%$ and $47.81 \%$, respectively, in addition of diterpenes and hydrocarbons as minors. Parveen et al. [24] described that the monoterpenoids are main components ( $55.80 \%)$, followed by sesquiterpenes $(26.40 \%)$, in addition to diterpenes and hydrocarbons as minors in the $\mathrm{EO}$ from leaves of $\mathrm{X}$. strumarium collected from Pakistan. However, the EO of leaves of Brazilian X. strumarium was stated to include the sesquiterpenes as main components $(88.13 \%)$ in addition to monoterpenes $(4.00 \%)$ without any diterpenes and hydrocarbons [31]. However, our study exhibited that the EO of leaves of Egyptian $X$. strumarium were close to the EO of Brazilian ecospecies, in which the sesquiterpenes are the main components $(72.40 \%)$. Meanwhile, our findings deduced that the Egyptian species are similar to the Pakistani and Iranian species in which the monoterpenes $(25.19 \%)$ represent the second major components, followed by the minors of hydrocarbons and diterpenes (Figure 2). 


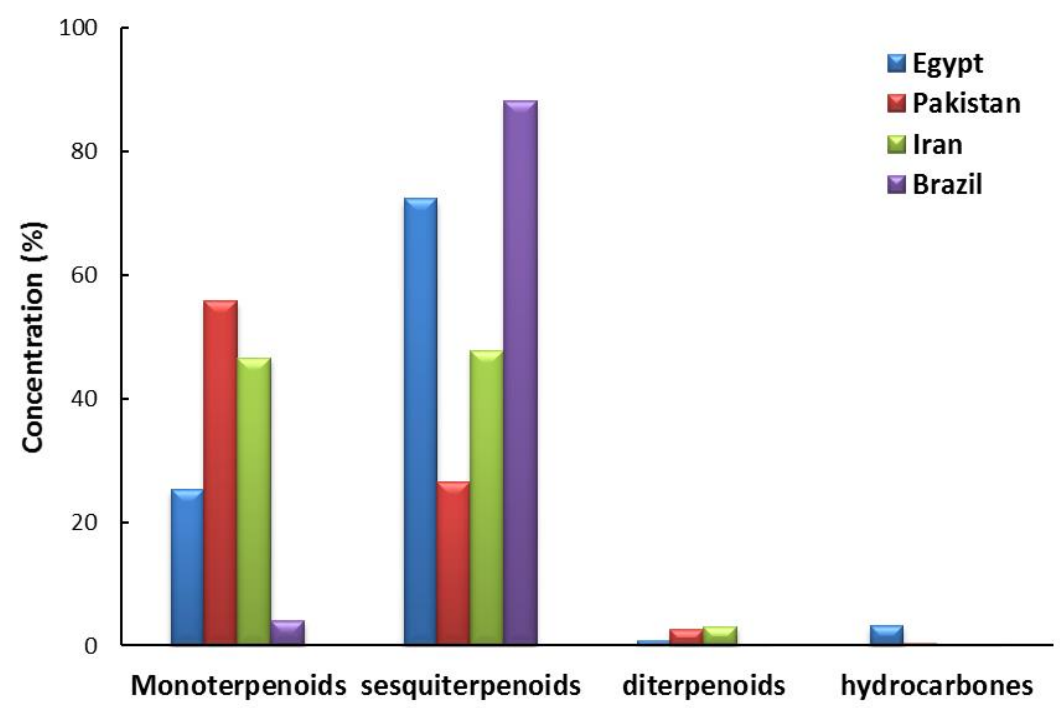

Figure 2. Percentage of various classes of the identified components in EOs from the leaves of X. strumarium from Egypt, as well as those reported from Pakistan [24], Iran [23,25], and Brazil [31].

In conclusion of our chemical study, the variations of the chemical composition of extracted EOs from plant species often occur, since the production of metabolites, involving EOs, is substantially influenced by environmental factors such as seasonality, age, plant development, circadian rhythm, temperature, water availability, altitude, nutrients, atmospheric composition, the different plant organs, and attack of pathogens and herbivores [32,33].

\subsection{Principal Components Analysis (PCA) and Agglomerative Hierarchical Clustering (AHC)}

In order to assess the correlation between the Egyptian ecospecies as well as Pakistani [24], Iranian [23,25], and Brazilian [31] ecospecies, the GC-MS data of the major compounds of the EO was subjected to PCA. The PCA horizontal axis explained $38.55 \%$ of the total variance, while the vertical axis explained a further $22.59 \%$ (Figure 3A). It is clear that both Iranian ecospecies (Iran-Sistan and Iran-Lurestan) are significantly correlated with each other as well, and are also correlated with the Pakistani ecospecies (Figure 3A and Table 2). However, the Egyptian ecospecies did not show any correlation with all of the other ecospecies.

Table 2. Correlation matrix (Pearson) between the locations of sampling based on the chemical composition of the EO of both Egyptian X. strumarium ecospecies and other ecospecies.

\begin{tabular}{cccccc}
\hline Location & Egypt & Iran-Sistan & Iran-Lurestan & Pakistan & Brazil \\
\hline Egypt & 1 & - & - & - & - \\
Iran-Sistan & -0.11 & 1 & - & - & - \\
Iran-Lurestan & -0.11 & $\mathbf{0 . 5 4}$ & 1 & - & - \\
Pakistan & -0.08 & 0.13 & $\mathbf{0 . 2 6}$ & 1 & - \\
Brazil & -0.04 & -0.01 & -0.01 & 0.02 & 1 \\
\hline
\end{tabular}

Values in bold are different from zero, with a significance level alpha $=0.05$.

The major compounds of the Egyptian ecospecies (1,5-dimethyltetralin, eudesmol, (-)-spathulenol, 1-borneol, ledene alcohol, caryophyllene oxide, isolongifolene, 7,8-dehydro-8a-hydrox-, and aristolene epoxide) had high positive loading on PC1. However, spathulenol seems to be more correlated with the Pakistani ecospecies than the Egyptian species.

On the other hand, both Iranian ecospecies showed significant correlation with borneol, bornyl acetate, cis- $\beta$-guaiene, limonene, sabinene, $\alpha$-cadinol, and $\beta$-cubebene. Meanwhile, the Pakistani ecospecies seemed to be more correlated with the Iranian ecospecies, where they were correlated 
through limonene. However, Pakistani showed a close correlation to $\beta$-caryophyllene and $\alpha$-cadinol. This correlation between these two ecospecies could be ascribed to the similarity of the geographical region's environmental and climatic conditions, as well as the genetic relation [34,35]. The Brazilian ecospecies did not show any correlation with other ecospecies, while it showed a close correlation with $\beta$-guaiene.
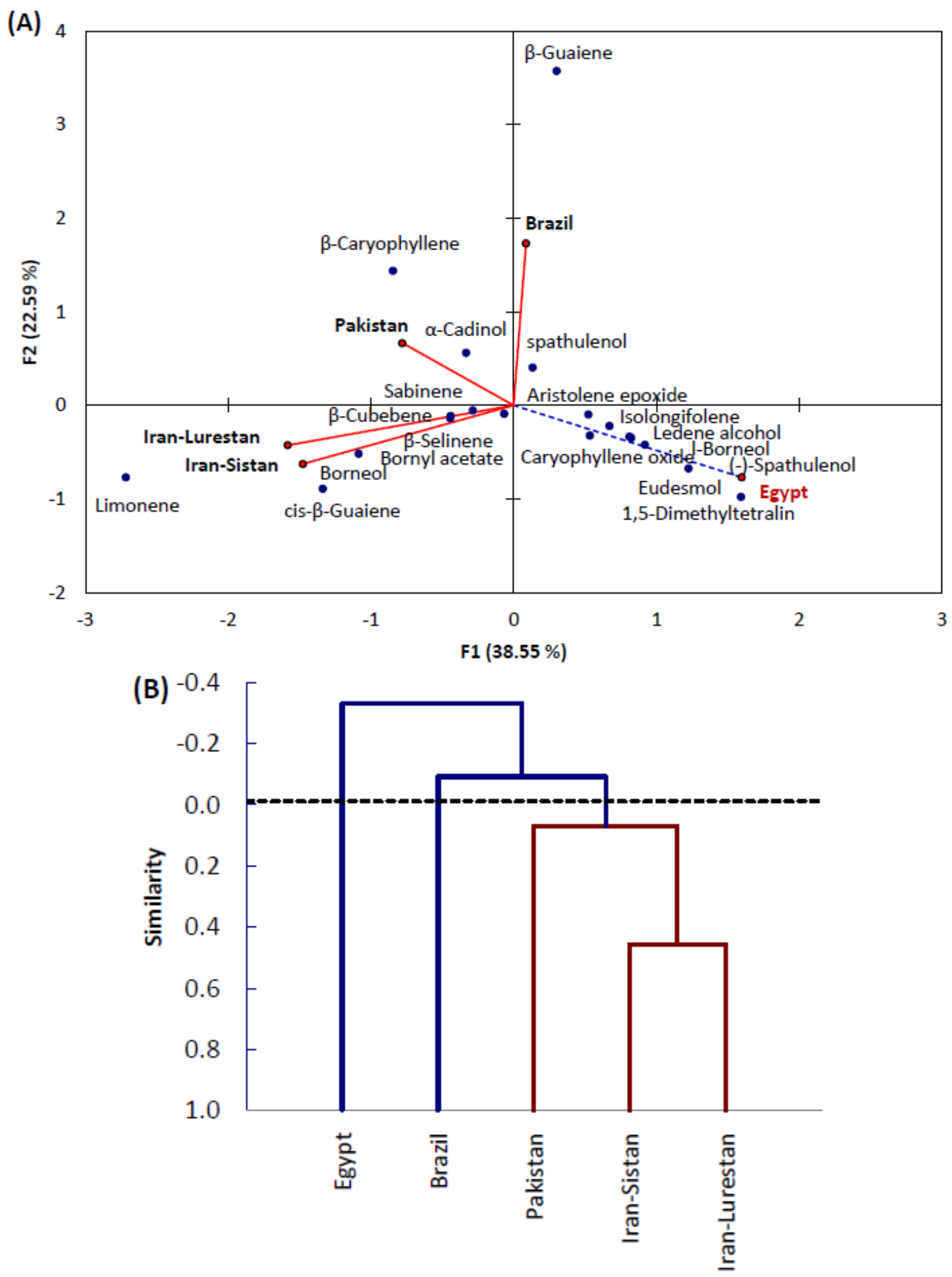

Figure 3. (A) Principal component analysis (PCA) and (B) agglomerative hierarchical clustering (AHC) based on the chemical composition of the EO derived from Egyptian ecospecies of X. strumarium leaves as well as Pakistani, Iranian, and Brazilian ecospecies. 
Agglomerative hierarchical clustering (AHC) based on the similarity led to the recognition of three groups (Figure 3B). Group I comprised both the Iranian ecospecies (Iran-Sistan and Iran-Lurestan) and Pakistani ecospecies, group II contained the Brazilian ecospecies, and finally group III comprised the Egyptian ecospecies. Generally, we can say that the chemical composition of the EO from the $X$. strumarium leaves of Egyptian ecospecies is completely not correlated to other ecospecies. This could be attributed to the variation in climatic conditions, environmental factors, the age of the plant, and extraction techniques [36].

\subsection{Allelopathic Activity}

$X$. strumarium EO showed a significant allelopathic activity on the germination and growth of the noxious weed B. pilosa in a concentration-dependent manner (Table 3). At higher concentrations $\left(1000 \mu \mathrm{L} \mathrm{L}^{-1}\right)$, the germination of seeds, root, and shoot growth were inhibited by $97.34 \%, 98.45 \%$, and $93.56 \%$, respectively. This strong inhibition could be attributed to the major compounds reported in the EO such as eudesmol, (-)-spathulenol, l-borneol, ledene alcohol, caryophyllene oxide, isolongifolene, 7,8-dehydro-8a-hydroxy, and aristolene epoxide, where these compounds may act either singular or synergetic as allelopathic agents against weeds. These are mainly oxygenated sesquiterpenes where they were reported to have various biological activities, including allelopathic activity [37,38].

Table 3. Allelopathic activity of the EO from Egyptian X. strumarium on the inhibition of seed germination, root, and shoot growth of Bidens pilosa after five days of treatment.

\begin{tabular}{|c|c|c|c|c|c|}
\hline \multirow{2}{*}{ Treatment } & \multicolumn{4}{|c|}{ Concentration $\left(\mu \mathrm{L} \mathrm{L}^{-1}\right)$} & \multirow{2}{*}{$\mathrm{LSD}_{0.05}$} \\
\hline & 250 & 500 & 750 & 1000 & \\
\hline Germination & $70.43^{\mathrm{c}} \pm 1.78$ & $82.47^{b} \pm 2.09$ & $90.77^{\mathrm{a}} \pm 2.30$ & $97.34^{\mathrm{a}} \pm 2.46$ & 7.08 \\
\hline Root & $65.42^{\mathrm{d}} \pm 1.65$ & $82.65^{c} \pm 2.06$ & $90.52^{b} \pm 2.29$ & $98.45^{\mathrm{a}} \pm 0.52$ & 5.99 \\
\hline Shoot & $48.56^{\mathrm{d}} \pm 1.23$ & $73.42^{\mathrm{c}} \pm 1.86$ & $84.52^{b} \pm 2.14$ & $93.56^{\mathrm{c}} \pm 2.15$ & 6.34 \\
\hline
\end{tabular}

Different letters within each row indicate values significant variation $p \leq 0.05$.

The sesquiterpene $\alpha$-eudesmol has wide interesting bioactivity, such as anticancer, antifeedant, plant growth regulation [39], and antimicrobial activity [40]. Moreover, Abd El-Gawad et al. [41] refered to the allelopathic potential of Rhynchosia minima to the high concentration of eudesmol. In addition, borneol [42] and caryophyllene oxide [7] were also reported to possess allelopathic activity.

B. pilosa is a noxious weed species, where it reduces the yield in several crops due to its fast growth and potential competitive activity [43]. It is worth mentioning here that the EO from X. strumarium in the present study revealed double fold the allelopathic activity against B. pilosa than those from Cullen plicata [7]. Therefore, we can say that the X. strumarium EO could be considered as a potential green source for bioherbicides, at least against the noxious weed B. pilosa; it can also be integrated into the eco-friendly weed control strategies. However, further investigation is needed in order to characterize its mode of actions, as well as the biosafety in the application at the field level.

\subsection{Antioxidant Activity}

The antibacterial, antifungal, and scolicidal activity EO of the leaves of X. strumarium collected from Pakistan [24] and Iran $[23,25]$ were evaluated. Herein, the DPPH radical scavenging activity of EO from leaves of Egyptian ecospecies of X. strumarium was evaluated for the first time.

In our study, the capabilities of X. strumarium essential oil to donate hydrogen atoms or electrons were evaluated spectrophotometrically. The ability of the tested oil to possess antioxidant activity by the reduction of DPPH to diphenyl-picrylhydrazine (the yellow-colored product), and decreasing the absorbance at $517 \mathrm{~nm}$ comparable to ascorbic acid as a reference antioxidant agent. Our evaluation result exhibited that the EO of X. strumarium exhibited weak DPPH radical scavenging activities with $\mathrm{IC}_{50} 321.93 \mu \mathrm{L} \mathrm{L}^{-1}$ by comparable to $35.07 \mu \mathrm{L} \mathrm{L}^{-1}$ for ascorbic acid (Table 4). 
Table 4. Antioxidant activity of the EO from Egyptian X. strumarium and ascorbic acid as standard.

\begin{tabular}{cc}
\hline Concentration $\left(\boldsymbol{\mu L ~ L ^ { - 1 } )}\right.$ & Scavenging (\%) * \\
\hline 500 & $58.45^{\mathrm{a}} \pm 1.19$ \\
400 & $52.52^{\mathrm{b}} \pm 0.79$ \\
300 & $50.20^{\mathrm{b}} \pm 1.32$ \\
200 & $45.16^{\mathrm{c}} \pm 1.56$ \\
100 & $38.56^{\mathrm{d}} \pm 0.71$ \\
\hline $\mathrm{LSD}_{0.05}$ & 4.18 \\
\hline $\mathrm{IC}_{50} \mu \mathrm{L} \mathrm{L}^{-1}$ & 321.93 \\
$\mathrm{IC}_{50}$ Ascorbic acid & 35.07 \\
\hline
\end{tabular}

* Values expressed are means \pm standard error of three samples. LSD $_{0.05}$ : least significant difference at $p \leq$ 0.05 . Different letters indicate values significant variation. $\mathrm{IC}_{50}$ : the amount of sample necessary to decrease the absorbance of DPPH (2,2-Diphenyl-1-picrylhydrazyl) by $50 \%$.

Mata et al. [44] reported that the weak DPPH radical scavenging activity of the terpene components can be attributed to them not having the ability to donate hydrogen atoms and their low solubility in the medium of the assay. Thus, the EO of X. strumarium exhibiting weak activity can be attributed to the main constituents of the oil being almost monoterpene and sesquiterpene hydrocarbons. According to Viuda-Martos et al. [45] and Andrade et al. [32], these previous factors may be the main limitation of measuring the DPPH radical scavenging activity of lipophilic samples, similar to many essential oils. In addition, Ruberto and Baratta [46], the presence of methylene group molecules may play an important role in increasing the antioxidant behavior. So, the weak antioxidant activity of EO of X. strumarium is attributed to the major compounds in this oil being monoterpenes and sesquiterpenes hydrocarbons and/or substituted oxygenated ones. Our finding is consistent with that reported from the EO extracted from the Brazilian ecospecies of X. strumarium [31].

\section{Material and Methods}

\subsection{Plant Material}

The leaves of X. strumarium were collected in the flowering stage in March 2017 from El-Salhia region, Al-Sharkia Province, Egypt $\left(30^{\circ} 38^{\prime} 59^{\prime \prime} \mathrm{N} 31^{\circ} 57^{\prime} 53^{\prime \prime} \mathrm{E}\right)$. The collected plant was identified by one from the author, Associate Professor Ahmed M. Abd El-Gawad. A voucher specimen (Mans.001024019) was deposited in the herbarium of Botany Department Faculty of Science, Mansoura University, Egypt.

\subsection{Extraction of EO}

The EO of the fresh leaves $(300 \mathrm{~g})$ of X. strumarium $(0.021 \mathrm{~mL})$ was extracted by hydrodistillation using a Clevenger-type apparatus for three hours. The oily layer was separated using diethyl ether and dried with anhydrous sodium sulfate $(0.5 \mathrm{~g})$. This extraction was repeated two times, which afforded two samples of EO. The extracted two samples of EO were stored in sealed air-tight glass vials at $4{ }^{\circ} \mathrm{C}$ until further analysis.

The EO components of the two extracted samples were analyzed separately and identified depending upon GC-MS analysis. The GC-MS analysis of the EO samples were carried out using gas chromatography-mass spectrometry instrument stands at the Department of Medicinal and Aromatic Plants Research, National Research Center, Dokki, Giza, Egypt with the following specifications, Instrument: a TRACE GC Ultra Gas Chromatographs (THERMO Scientific Corp., Miami, CA, USA), coupled with a thermo mass spectrometer detector (ISQ Single Quadrupole Mass Spectrometer; Model ISQ spectrometer, THERMO Scientific Corp. ). The GC-MS system was equipped with a TR-5 MS column (30 $\mathrm{m} \times 0.32 \mathrm{mmi}$.d., $0.25-\mu \mathrm{m}$ film thickness, THERMO Scientific Corp. ). Analyses were carried out using helium as a carrier gas at a flow rate of $1.0 \mathrm{~mL} \mathrm{~min}^{-1}$ and a split ratio of 1:10 using the following temperature program: $60^{\circ} \mathrm{C}$ for one minute; rising at $4.0^{\circ} \mathrm{C} \mathrm{min}-1$ to $240{ }^{\circ} \mathrm{C}$, and held 
for one minute. The injector and detector were held at $210{ }^{\circ} \mathrm{C}$. Diluted samples $(1: 10$ hexane, $v / v)$ of one $\mu \mathrm{L}$ of the mixtures were always injected. Mass spectra were obtained by electron ionization (EI) at $70 \mathrm{eV}$, using a spectral range of $m / z 40-450$.

\subsection{Identification of EO Constituents}

The identification of the chemical constituents of the EO was deconvoluted using AMDIS software (NIST, Gaithersburg, MD, USA; Wiley, Hoboken, NJ, USA) and identified by its retention indices (relative to $n$-alkanes $\mathrm{C}_{8}-\mathrm{C}_{22}$ ), mass spectrum matching to authentic standards (when available), the Wiley spectral library collection, and the NSIT library database.

\subsection{Allelopathic Activity}

The leaves of X. strumarium were collected from different orchards cultivated with mango trees at El-Salhia region, Al-Sharkia Governorate, Egypt ( $\left.30^{\circ} 38^{\prime} 59^{\prime \prime} \mathrm{N} 31^{\circ} 57^{\prime} 53^{\prime \prime} \mathrm{E}\right)$. The collected samples were cleaned from dust, dried in a shaded place at room temperature $\left(27^{\circ} \mathrm{C} \pm 2\right)$, ground, and packed in a paper bag until further use. However, the seeds of Bidens pilosa were collected from a garden of Mansoura University, Mansoura, Egypt ( $\left.31^{\circ} 02^{\prime} 40.9^{\prime \prime} \mathrm{N} 31^{\circ} 21^{\prime} 17.8^{\prime \prime} \mathrm{E}\right)$.

In order to assess the allelopathic potential of the EO, various concentrations $\left(250 \mu \mathrm{L} \mathrm{L}^{-1}\right.$, $500 \mu \mathrm{L} \mathrm{L}^{-1}, 750 \mu \mathrm{L} \mathrm{L}^{-1}$, and $1000 \mu \mathrm{L} \mathrm{L}^{-1}$ ) of the extracted EO were prepared using Tween ${ }^{\circledR} 80$ (Sigma-Aldrich, Germany), at the ratio 1:1 $(v / v)$. The seeds were sterilized using 0.3\% sodium hypochlorite for three minutes, followed by washing with distilled water and drying over sterilized filter paper. Subsequently, 20 seeds were transferred to sterilized Petri plates (nine centimeters) lined with two layers of Whatman No. 1 filter papers. An aliquot of four mL of either the EOs or Tween as control was added to the plates and sealed with a Parafilm ${ }^{\circledR}$ tape (Sigma, USA) and kept at $27^{\circ} \mathrm{C}$ in a growth chamber (Abd El-Gawad, 2016).

After five days of incubation, the germinated seeds were counted, and the length of the root and shoot were measured. The inhibition of germination or seedling length was calculated as follows:

$$
\text { Inhibition }(\%)=100 \times \frac{(\mathrm{No} / \text { Length of control }-\mathrm{No} / \text { Length of tretamnet })}{\mathrm{No} / \text { Length of control }}
$$

\subsection{Antioxidant Activity}

The antioxidant activity of the EO was measured based on the radical scavenging activity of the stable radical, 2,2-diphenyl-1-picrylhydrazyl (DPPH) (Sigma-Aldrich, Darmstadt, Germany) according to the methods of Miguel [47]. A reaction mixture of one $\mathrm{mL}$ of different concentrations of the EO and an equal volume of the alcoholic solution of $0.3 \mathrm{mM}$ of DPPH were prepared, mixed well, and incubated in the dark for 15 minutes at room temperature $\left(25^{\circ} \mathrm{C}\right)$. In addition, various concentrations of ascorbic (standard antioxidant) were subjected to the same procedures. The absorbance at $517 \mathrm{~nm}$ was determined using a spectrophotometer (Spectronic 21D model, Milton Roy, CA, USA). The $\mathrm{IC}_{50}$, which is the amount of material necessary to decrease the absorbance of DPPH by $50 \%$, was calculated graphically.

\subsection{Statistical Analysis}

The data of both allelopathy and antioxidant, in triplicates, were subjected to one-way ANOVA followed by Duncan's test at a probability level of 0.05 using the COSTAT software program. However, the data derived from the GC-MS analysis of Egyptian ecospecies and of other reported ecospecies (Pakistani, Iranian, and Brazilian) were subjected to an agglomerative hierarchical cluster (AHC) based on 80 identified chemical compounds. We also constructed a matrix of correlation by a principal component analysis (PCA) to identify whether a significant difference exists between different ecospecies. Both AHC and PCA were performed using XLSTAT statistical computer software package, version 14 (Addinsoft, New York, NY, USA). 


\section{Conclusions}

The present study revealed that the chemical composition of the EO from the leaves of $X$. strumarium, an Egyptian ecospecies, was different from other ecospecies reported from Pakistan, Iran, and Brazil. This difference could be attributed to the variation in climatic and environmental conditions. The Egyptian X. strumarium ecospecies EO contained 43 compounds with major constituents related to sesquiterpenoids. The main constituents were 1,5-dimethyltetralin, eudesmol, l-borneol, ledene alcohol, (-)-caryophyllene oxide, isolongifolene, 7,8-dehydro-8a-hydroxy, L-bornyl acetate, and aristolene epoxide. The EO showed weak antioxidant activity. However, the EO showed strong allelopathic activity against the weed, B. pilosa, which considered as strong nuisance weeds. Therefore, further study is recommended to characterize the mode of actions of the EO from X. strumarium as well as determine the biosafety of the integration of this EO as a bioherbicide in agricultural practices as an eco-friendly, green tool.

Author Contributions: Conceptualization, A.A.E.-G. and A.E.; Data curation, A.A.E.-G.; Formal analysis, A.A.E.-G., A.E., A.E.-N.E.G. and A.G.; Investigation, A.A.E.-G. and A.E.; Methodology, A.A.E.-G., A.E. and A.E.-N.E.G.; Software, A.A.E.-G.; Writing—original draft, A.A.E.-G., A.E. and A.E.-N.E.G.; Writing一review \& editing, A.A.-G., A.E. and A.A.

Funding: This research was funded by Deanship of Scientific Research at King Saud University, through research group number RG-1440-113 and the APC was funded also by Deanship of Scientific Research at King Saud University.

Acknowledgments: The authors extend their appreciation to the Deanship of Scientific Research at King Saud University for funding this work through research group No (RG-1440-113). Also, authors like to sincere the Department of Botany, Faculty of Science, Mansoura University, and National Research Centre, Egypt (Project No: 11080302).

Conflicts of Interest: The authors declare that there is no conflict of interest.

\section{References}

1. Baratta, M.T.; Dorman, H.D.; Deans, S.G.; Biondi, D.M.; Ruberto, G. Chemical composition, antimicrobial and antioxidative activity of laurel, sage, rosemary, oregano and coriander essential oils. J. Essent. Oil Res. 1998, 10, 618-627. [CrossRef]

2. Piaru, S.P.; Mahmud, R.; Abdul Majid, A.M.S.; Ismail, S.; Man, C.N. Chemical composition, antioxidant and cytotoxicity activities of the essential oils of Myristica fragrans and Morinda citrifolia. J. Sci. Food Agric. 2012, 92, 593-597. [CrossRef]

3. Vyvyan, J.R. Allelochemicals as leads for new herbicides and agrochemicals. Tetrahedron 2002, 58, 1631-1636. [CrossRef]

4. Weston, L.A. Utilization of allelopathy for weed management in agroecosystems. Agron. J. 1996, 88, 860-866. [CrossRef]

5. Batish, D.R.; Singh, H.P.; Kohli, R.K.; Kaur, S. Eucalyptus essential oil as a natural pesticide. For. Ecol. Manag. 2008, 256, 2166-2174. [CrossRef]

6. Abd El-Gawad, A.; El Gendy, A.; Elshamy, A.; Omer, E. Chemical composition of the essential oil of Trianthema portulacastrum L. Aerial parts and potential antimicrobial and phytotoxic activities of its extract. J. Essent. Oil Bear. Pl. 2016, 19, 1684-1692. [CrossRef]

7. Abd El-Gawad, A.M. Chemical constituents, antioxidant and potential allelopathic effect of the essential oil from the aerial parts of Cullen plicata. Ind. Crop. Prod. 2016, 80, 36-41. [CrossRef]

8. Ens, E.J.; Bremner, J.B.; French, K.; Korth, J. Identification of volatile compounds released by roots of an invasive plant, bitou bush (Chrysanthemoides monilifera spp. rotundata), and their inhibition of native seedling growth. Biol. Invas. 2009, 11, 275-287. [CrossRef]

9. Saharkhiz, M.J.; Smaeili, S.; Merikhi, M. Essential oil analysis and phytotoxic activity of two ecotypes of Zataria multiflora Boiss. growing in Iran. Nat. Prod. Res. 2010, 24, 1598-1609. [CrossRef]

10. Joshi, S.; Rojatkar, S.; Nagasampagi, B. Antimalarial activity of Xanthium strumarium. J. Med. Aromat. Pl. Sci. 1997, 19, 366-368. 
11. Kinghorn, A.; Farnsworth, N.; Soejarto, D.; Cordell, G.; Swanson, S.; Pezzuto, J.; Wani, M.; Wall, M.; Oberlies, N.; Kroll, D. Novel strategies for the discovery of plant-derived anticancer agents. Pharm. Biol. 2003, 41, 53-67. [CrossRef]

12. Kamboj, A.; Saluja, A.K. Phytopharmacological review of Xanthium strumarium L.(Cocklebur). Int. J. Green Pharm. 2010, 4, 129-139. [CrossRef]

13. Ginesta-Peris, E.; Garcia-Breijo, F.-J.; Primo-Yúfera, E. Antimicrobial activity of xanthatin from Xanthium spinosum L. Letters in Applied Microbiology 1994, 18, 206-208. [CrossRef]

14. Tsankova, E.T.; Trendafilova, A.B.; Kujumgiev, A.I.; Galabov, A.S.; Robeva, P.R. Xanthanolides of Xanthium italicum Moretti and their biological activity. Z. Naturforsch. C 1994, 49, 154-156. [CrossRef]

15. Talakal, T.; Dwivedi, S.; Sharma, S. In vitro and in vivo antitrypanosomal activity of Xanthium strumarium leaves. J. Ethnopharmacol. 1995, 49, 141-145. [CrossRef]

16. Qin, L.; Han, T.; Li, H.; Zhang, Q.; Zheng, H. A new thiazinedione from Xanthium strumarium. Fitoterapia 2006, 77, 245-246. [CrossRef]

17. Han, T.; Li, H.-L.; Zhang, Q.-Y.; Han, P.; Zheng, H.-C.; Rahman, K.; Qin, L.-P. Bioactivity-guided fractionation for anti-inflammatory and analgesic properties and constituents of Xanthium strumarium L. Phytomedicine 2007, 14, 825-829. [CrossRef] [PubMed]

18. Yoon, J.H.; Lim, H.J.; Lee, H.J.; Kim, H.-D.; Jeon, R.; Ryu, J.H. Inhibition of lipopolysaccharide-induced inducible nitric oxide synthase and cyclooxygenase-2 expression by xanthanolides isolated from Xanthium strumarium. Bioorg. Med. Chem. Lett. 2008, 18, 2179-2182. [CrossRef]

19. Shah, F.; Ahmad, N.; Zahid, D.; Masood, K.; Ahmad, S. The hudiara drain waste water effect on the distribution of surrounding herbaceous vegetation. Pak. J. Bot. 2010, 42, 1745-1754.

20. Yadava, R.; Jharbade, J. Novel biologically active triterpenoid saponin from the leaves of Xanthium strumarium Linn. Asian J. Chem. 2007, 19, 1224-1230.

21. Sheu, S.J.; Hsu, F.L.; Tai, H.M.; Sheu, M.J.; Huang, M.H. Determination of xanthii constituents by high-performance liquid chromatography and capillary electrophoresis. J. Food Drug Anal. 2003, 11, 67-71.

22. Saxena, V.; MISHRA, M. Xanthanolides from Xanthium strumarium. Fitoterapia 1995, 66, 159-161. [CrossRef]

23. Esmaeili, A.; Rustaiyan, A.; Akbari, M.T.; Moazami, N.; Masoudi, S.; Amiri, H. Composition of the essential oils of Xanthium strumarium L. and Cetaurea solstitialis L. from Iran. J. Essent. Oil Res. 2006, 18, 427-429. [CrossRef]

24. Parveen, Z.; Mazhar, S.; Siddique, S.; Manzoor, A.; Ali, Z. Chemical composition and antifungal activity of essential oil from Xanthium strumarium L. leaves. Indian J. Pharm. Sci. 2017, 79, 316-321. [CrossRef]

25. Sharifi-Rad, J.; Hoseini-Alfatemi, S.M.; Sharifi-Rad, M.; Sharifi-Rad, M.; Iriti, M.; Sharifi-Rad, M.; Sharifi-Rad, R.; Raeisi, S. Phytochemical compositions and biological activities of essential oil from Xanthium strumarium L. Molecules 2015, 20, 7034-7047. [CrossRef] [PubMed]

26. Medeiros, R.T.d.S.; Gonçalez, E.; Felicio, R.C.; Felicio, J. Evaluation of antifungal activity of Pittosporum undulatum L. essential oil against Aspergillus flavus and aflatoxin production. Cienc. Agrotec. 2011, 35, 71-76. [CrossRef]

27. Khazaie, H.R.; Nadjafi, F.; Bannayan, M. Effect of irrigation frequency and planting density on herbage biomass and oil production of thyme (Thymus vulgaris) and hyssop (Hyssopus officinalis). Ind. Crop. Prod. 2008, 27, 315-321. [CrossRef]

28. Bounatirou, S.; Smiti, S.; Miguel, M.G.; Faleiro, L.; Rejeb, M.N.; Neffati, M.; Costa, M.; Figueiredo, A.; Barroso, J.; Pedro, L. Chemical composition, antioxidant and antibacterial activities of the essential oils isolated from Tunisian Thymus capitatus Hoff. et Link. Food Chem. 2007, 105, 146-155. [CrossRef]

29. Costa, L.C.B.; Pinto, J.E.B.P.; Bertolucci, S.K.V.; Costa, J.C.d.B.; Alves, P.B.; Niculau, E.d.S. In vitro antifungal activity of Ocimum selloi essential oil and methylchavicol against phytopathogenic fungi. Rev. Cienc. Agron. 2015, 46, 428-435. [CrossRef]

30. Li, Z.J.; Njateng, G.S.; He, W.J.; Zhang, H.X.; Gu, J.L.; Chen, S.N.; Du, Z.Z. Chemical composition and antimicrobial activity of the essential oil from the edible aromatic plant Aristolochia delavay. Chem. Biodivers. 2013, 10, 2032-2041. [CrossRef]

31. Scherer, R.; Wagner, R.; Meireles, M.; Godoy, H.; Duarte, M.; Filho, J. Biological activity and chemical composition of hydrodistilled and supercritical extracts of Xanthium strumarium L. leaves. J. Essent. Oil Res. 2010, 22, 424-429. [CrossRef] 
32. Andrade, M.A.; das Graças Cardoso, M.; de Andrade, J.; Silva, L.F.; Teixeira, M.L.; Valério Resende, J.M.; da Silva Figueiredo, A.C.; Barroso, J.G. Chemical composition and antioxidant activity of essential oils from Cinnamodendron dinisii Schwacke and Siparuna guianensis Aublet. Antioxidants 2013, 2, 384-397. [CrossRef] [PubMed]

33. Bakkali, F.; Averbeck, S.; Averbeck, D.; Idaomar, M. Biological effects of essential oils-a review. Food Chem. Toxicol. 2008, 46, 446-475. [CrossRef] [PubMed]

34. Vinceti, B.; Loo, J.; Gaisberger, H.; van Zonneveld, M.J.; Schueler, S.; Konrad, H.; Kadu, C.A.; Geburek, T. Conservation priorities for Prunus africana defined with the aid of spatial analysis of genetic data and climatic variables. PLoS ONE 2013, 8, e59987. [CrossRef]

35. Pérez-Sánchez, R.; Gálvez, C.; Ubera, J.L. Bioclimatic influence on essential oil composition in South Iberian Peninsular populations of Thymus zygis. J. Essent. Oil Res. 2012, 24, 71-81. [CrossRef]

36. Abd El-Gawad, A.M.; El-Amier, Y.A.; Bonanomi, G. Essential oil composition, antioxidant and allelopathic activities of Cleome droserifolia (Forssk.) Delile. Chem. Biodivers. 2018, 15, e1800392. [CrossRef]

37. Padilla-Gonzalez, G.F.; dos Santos, F.A.; Da Costa, F.B. Sesquiterpene lactones: More than protective plant compounds with high toxicity. Crit. Rev. Plant Sci. 2016, 35, 18-37. [CrossRef]

38. Macías, F.A.; Galindo, J.C.G.; Massanet, G.M. Potential allelopathic activity of several sesquiterpene lactone models. Phytochemistry 1992, 31, 1969-1977. [CrossRef]

39. Paul, V.J.; Cronan, J.M.; Cardellina, J.H. Isolation of new brominated sesquiterpene feeding deterrents from tropical green alga Neomeris annulata (Dasycladaceae: Chlorophyta). J. Chem. Ecol. 1993, 19, 1847-1860. [CrossRef]

40. Demirci, F.; Guven, K.; Demirci, B.; Dadandi, M.; Baser, K. Antibacterial activity of two Phlomis essential oils against food pathogens. Food Control 2008, 19, 1159-1164. [CrossRef]

41. Abd El-Gawad, A.M.; El-Amier, Y.A.; Bonanomi, G. Allelopathic activity and chemical composition of Rhynchosia minima (L.) DC. essential oil from Egypt. Chem. Biodivers. 2018, 15, e1700438. [CrossRef] [PubMed]

42. Oster, U.; Spraul, M.; Rüdiger, W. Natural inhibitors of germination and growth, V possible allelopathic effects of compounds from Thuja occidentalis. Z. Naturforschung C 1990, 45, 835-844. [CrossRef]

43. Holm, L.G.; Plucknett, D.L.; Pancho, J.V.; Herberger, J.P. The World's Worst Weeds: Distribution and Biology; University Press of Hawaii: Honolulu, HI, USA, 1977.

44. Mata, A.; Proença, C.; Ferreira, A.; Serralheiro, M.; Nogueira, J.; Araújo, M. Antioxidant and antiacetylcholinesterase activities of five plants used as Portuguese food spices. Food Chem. 2007, 103, 778-786. [CrossRef]

45. Viuda-Martos, M.; Ruiz Navajas, Y.; Sánchez Zapata, E.; Fernández-López, J.; Pérez-Álvarez, J.A. Antioxidant activity of essential oils of five spice plants widely used in a Mediterranean diet. Flavour Fragr. J. 2010, 25, 13-19. [CrossRef]

46. Ruberto, G.; Baratta, M.T. Antioxidant activity of selected essential oil components in two lipid model systems. Food Chemistry 2000, 69, 167-174. [CrossRef]

47. Miguel, M.G. Antioxidant activity of medicinal and aromatic plants. Flavour Fragr. J. 2010, 25, $291-312$. [CrossRef]

Sample Availability: Samples of the compounds are not available from the authors. 